ISSN 1518-3483

Licenciado sob uma Licença Creative Commons

\title{
Ética e complexidade na formação de professores
}

\author{
Ethics and complexity in teacher's education
}

Ética y complexidade en la formación de profesores

\author{
Ana Paula Caetano* \\ Instituto de Educação, Universidade de Lisboa, Lisboa, Portugal
}

\section{Resumo}

No presente texto apresentamos uma reflexão sobre ética em geral e sobre ética na educação, tendo implícita a mobilização de uma visão complexa. Apresentamos ainda pesquisas efetuadas no domínio do pensamento ético e da formação ética de professores, realizadas no âmbito do Instituto de Educação da Universidade de Lisboa, nomeadamente os resultados de um projeto de investigação em que temos estado envolvidos no Instituto de Educação da Universidade de Lisboa, intitulado "Pensamento e Formação ético-deontológicos de professores" e de investigações que lhe deram continuidade ou que, de algum modo, com ele estão relacionados. Também aqui se faz uma articulação com as perspetivas da complexidade, nomeadamente na análise das mudanças identificadas pelos e nos professores e que estes associam à formação. O capítulo termina com uma reflexão final onde se questionam e se desconstroem algumas opções teóricas e metodológicas e tecem-se algumas linhas que desenham uma modelização da formação ética de professores,

* APC: Doutora em Ciências da Educação, e-mail: apcaetano@ie.ulisboa.pt 
entendendo no entanto que este exercício é apenas uma aproximação a possíveis formas de trabalhar com os professores e educadores, nomeadamente em contextos de formação contínua.

Palavras-chave: Ética. Complexidade. Formação de professores.

\begin{abstract}
In this paper we present a reflection on ethics in general and ethics in education, having implied the mobilization of a complex vision. We also present researches done in the field of ethical thought and ethics in teacher's education, carried out under the Institute of Education, University of Lisbon, including the results of a research project in which we have been engaged at the Institute of Education, University of Lisbon, entitled "Thought and ethical and deontological teacher's education" and research that gave continuity or that, somehow, with it are related. Also here is a link with the prospects of complexity, particularly in the analysis of changes identified by and in teachers and they associate with teacher's education. The chapter ends with a final reflection where it is questioned and deconstructed some theoretical and methodological options and weaved a few lines drawing a modeling of ethics in teacher's education, understanding, however, that this exercise is only an approximation of possible ways to work with teachers and educators, particularly in continuation education contexts.
\end{abstract}

Keywords: Ethics. Complexity. Teacher's education.

\title{
Resumen
}

En este artículo se presenta una reflexión sobre la ética en general y la ética en la educación, e implicaba la movilización de una visión compleja. También presentamos la investigación realizada en el campo del pensamiento ético y la formación ética de; maestro, llevado a cabo en el marco del Instituto de Educación, Universidad de Lisboa, incluyendo los resultados de un proyecto de investigación en los que hemos participado en el Instituto 
de Educación de la Universidad de Lisboa, titulado "Pensamiento y ética y deontológica en la formación del profesorado" y la investigación que dio continuidad o que, de alguna manera, con él se relacionan. También aquí hay un enlace con la perspectiva de la complejidad, particularmente en el análisis de los cambios identificados en y por los profesores y la formación y que ellos asocian a ella. El capítulo termina con una reflexión final donde hay la pregunta y deconstrucción de algunas opciones teóricas y metodológicas y hay un tejer un par de líneas de dibujo de una formación ética de los ejemplos del maestro, la comprensión sin embargo, que este ejercicio es sólo una aproximación de las posibles formas de trabajar con maestros y educadores, particularmente en contextos de formación.

Palabras clave: Ética. Complexidad. Formación de profesores.

\section{Introdução}

La finalité éthique a deux faces complémentaires. La première est la résistance à la cruauté et à la barbarie. La seconde est l'accomplissement de la vie humaine (MORIN, 2004, p. 230).

Começo esta reflexão com a intuição de que ela nos permitirá conduzir ao que ainda não sei. Porque só isso faz sentido. Caminhar aberto ao inesperado que em cada esquina, de uma palavra, de uma linha, de um parágrafo nos permitirá superar-nos. Convido-vos a caminhar comigo. Para que encontrem os vossas próprias e inesperadas descobertas. Não exatamente as minhas. Para que, pela diversidade e pelo diálogo, nos seja possível o encontro. Porque será junto com o outro, respirando junto, sentindo a vibração no coração nosso, que a aventura de viver fará sentido.

A busca do sentido, incessante interrogação da qual tantas vezes nos perdemos, mas que retomando nos coloca de novo no caminho da consciência. E com a busca do sentido vem a interrogação do Bem, como o sentido a que se aspira, como o sentido que se alcança em cada momento, porque não fará sentido desloca-lo para um tempo sempre à frente e a que 
nunca se chega. E com o Bem logo nos aflige o Mal, esse sentido que é o seu contraponto, e que no nosso modo de pensar dicotómico e linear nos surge como algo a evitar, a desfazer, contra o qual lutar. E assim entramos num processo criativo, que só às vezes é pacífico. Embora possa ser bem mais, quando uma compreensão mais ampla, de um olhar distanciado nos faz ver o sentido mais vasto. Sabendo que fazemos parte de um jogo criativo, de encontros e confrontos, para que dele algo melhor, mais verdadeiro e mais belo se eleve e no qual todos possam ganhar. Um jogo em que não nos perderemos se soubermos não lhe pertencer inteiramente. Mantendo-nos libertos. A partir de dentro. Embora o que é dentro pareça por vezes ser fora. Porque o fora de nós, é dentro de algo certamente. E o caminho é trazê-lo para dentro de nós e levar-nos para dentro do que aparenta ser fora.

(Deixo-me dizer, pois assumo esta primeira parte como um dizer a partir de dentro, depois de esquecer tudo o que se pensou e leu e depois de só ter ficado o que agora importa ser dito).

Aprenderemos com a experiência, mas também com a educação que consciente e intencionalmente nos encaminhará ao encontro de nós mesmos e dos outros. Que nos deveria encaminhar, embora tantas vezes nos desvie. Podendo, no entanto, os desvios serem os necessários atalhos para algo que depois, só depois, será possível. A Humanidade caminha junta, mesmo que aparentemente seja desuna e diversa. Sê-lo-á também. Mas cada conquista e cada derrota no caminho ficará como uma marca para todos nós.

A Humanidade é em devir, para alguns em progresso, ao encontro de uma outra Humanidade que ainda não é. E em cada vida recomeçamos esse processo de sermos a criança e depois a mãe, o pai, não apenas ou necessariamente de um filho distinto, mas também de nós mesmos, que eventualmente, não sendo certo, renasceremos fecundados por algo, dentro de nós (eterno) e ao qual nos entregaremos plenamente, largando a pele e renovando-a numa nova, quiçá mais transparente. Um processo 
de individuação e emergência de uma nova ordem, mas que não fazemos sozinhos. Por não ser possível chegar lá sem que o conhecimento acumulado da humanidade inteira nos sustenha, sem o apoio de outros que, mais centrados, mais sábios, mais amorosos, mais diligentes, contaminem a nossa caminhada. Enquanto nós, no esmeril da aparente igualdade e desigualdade, nos confrontamos e contaminamos outros.

Em cada momento cruzamo-nos com aqueles com quem é possível fazer isso. Nós professores, com as nossas crianças e jovens alunos, fazemos isso. Não tanto, ou nem sequer, pelo conhecimento acumulado que transportamos. Não apenas pelo nosso exemplo de seres mais experientes e talvez íntegros. Não somente pelo poder do argumento ou pelos afetos. Também por tudo isso. Mas também porque abertos aos outros os escutamos, os sentimos gente, percebemos nos seus gestos e nas suas falas uma sabedoria que nos escapa ou que já perdemos. Porque aprendemos com eles no diálogo e no silêncio. No olhar atento aos movimentos que fora ressoam dentro. E porque ressoam dentro nos implicam, nos desafiam e nos transformam. E porque ao nos transformarmos dentro se torna possível transformarmos a interação e tocarmos os outros. Ressoando neles, dentro deles, transformando-se eles também. E assim aprendemos a ser crianças. Já não as mesmas que fomos, mas outras. Filhos das nossas crianças, dos nossos alunos, também.

Para isso é preciso, antes de mais, entregar-nos ao processo, num sentido que extravase a funcionarização de um emprego remunerado e que toca a raiz do nosso ser (embora a dignificação da profissão também passe pelo reconhecimento do seu valor, por via dessas questões laborais e das políticas públicas). Ao mesmo tempo um sentido de autodesenvolvimento e de serviço à Humanidade, finalidade que podemos abraçar ou negar e de cuja consciência e comprometimento depende o modo como exerceremos o ofício. Um ofício sagrado e um ofício profano ao mesmo tempo. Sabendo que não nos esgotamos nele, que dele se desprende o nosso ser mais profundo, que continuará o seu caminho depois do ofício se quedar. Embora possamos continuar ao serviço: de todos os que connosco se continuarão a cruzar ou, através de nós recolhidos, de 
um coletivo. Um coletivo que não é só social, cultural, político, ambiental, que não é só local mas também planetário, que não é só deste tempo, que atravessa os tempos, com implicações no presente, no futuro, quiçá no passado, caso o espaço-tempo não seja uma flecha num só sentido, e seja uma espiral e um remoinho cuja turbulência, hoje, influi simultaneamente, para trás e para a frente, para cima e para baixo, para dentro e para fora, não apenas na tridimensionalidade que nos é familiar, mas também nos planos que habitamos com o sopro, com a emoção, com a mente, com a intuição, com o espírito, dentro de seres mais vastos, sendo estes dentro de seres mais vastos, dentro de seres mais vastos... Este é também um desafio a pensar para além da nossa subjetividade e da perceção imediata da realidade.

Este é um discurso de esperança na humanidade, mas mais ainda do que de esperança, de convicção numa realidade em devir. Um discurso de esperança que ofereço, porque acredito. Acredito que somos bem mais do que parecemos, preciosos nos nossos pequenos gestos, interiores e exteriores. Acredito em nós, que somos parte de uma humanidade a caminho e porque, em cada um, toda a humanidade se reflete e nela nos refletimos. Cada um de nós é diferença e semelhança. Trazemos um grão, nosso singular contributo à humanidade. Será essa a nossa grandeza. Mas para que ela seja mais plena precisamos descobrir essa singularidade nossa. Um processo que não é adquirido à nascença, nem durante a infância. Há uma singularidade que aí se manifesta. Mas, qual borboleta, precisamos perceber que essa é só a primeira parte do caminho. Aí somos o embrião de outra coisa. De algo que talvez nos leve a vida inteira a realizar, que talvez mal cheguemos a começar e que interromperemos a meio.

À convicção vêm aliados o entusiasmo, a alegria, o amor. Somos movidos por energia, não apenas emoções, sentimentos circunstanciais e efémeros, mas por algo ainda mais profundo que é a vitalidade dos corpos individuais e coletivos, que nos direcionam e alimentam. Podemos sê-lo ainda mais, se a isso nos dispusermos e entregarmos. Com a pureza de propósitos e a integralidade do nosso ser. Para isso precisamos andar na vida para recuperar a nossa autenticidade de criança, a sua espontaneidade 
e confiança. Dirão que isso é uma utopia, uma ilusão e não existe. Essa criança nunca existiu e, caso tenha existido, não poderá voltar a sê-lo. Concordo que nunca nada será como já foi, mas será possível recuperar a simplicidade de se ser o que se é, acrescida da autoconsciência e da consciência do outro e da consciência de que no outro também se prolonga o eu e no eu o outro.

E aqui uma questão, um desafio, um entre muitos que a reflexão ética nos coloca: como ser e aceitar o que se é, percebendo em nós, nos nossos alunos, nas nossas crianças e jovens, o que de um ponto de vista social, crítico e valorativo pode ser julgado como bom ou mau, ao mesmo tempo que buscamos um aperfeiçoamento ou uma felicidade ou uma compreensão ou uma beleza que ainda não é e que vislumbramos como possível? Um equilíbrio difícil, ao qual respondo apelando a um olhar diferenciado, que trata cada um tendo em conta o que é e o que está prestes a tornar-se, ao invés de lhe impor um ideal longínquo

(reconhecer-se-á nestas palavras outras, de autores sobejamente reconhecidos, bem mais sapientes e especializados do que eu. Aproprio-me do seu pensamento como património imaterial da humanidade, que por eles nos foi ofertado mas que não possuem em exclusivo).

Não podemos pedir à criança que seja já adulto, nem a um adolescente que seja um outro, como não esperamos que uma rosa seja um narciso, que uma gazela seja um cisne, que um caranguejo seja um escaravelho. Nem lhes devemos cortar uma perna, uma cauda, uma antena, por nos parecer que serão mais belos sem elas. Temos de compreender a essência e a existência de cada um, o que é em cada momento, e o que pode ser ou não ser. E sem negar a sua natureza, sem procurar destruir nada que lhes seja inevitável e indispensável, ajudá-los a ser quem são e melhor ainda, integrando e transmutando partes. Qual flor de lótus que brilha enraizada e alimentada na lama, aproveitando-a como matéria-prima para ser outra coisa. E penso em toda a dificuldade que os professores 
sentirão ao conviverem com crianças e jovens com existências difíceis, mergulhados em realidades onde a violência se repercute dentro deles.

Fazê-lo com os outros implica fazê-lo connosco próprios, ao mesmo tempo aprendendo com eles.

Não fazermos de nós e do outro o inimigo, nem de cada aspeto que consideremos como defeito, um tumor a extirpar. Observar como tudo pode cooperar para fazer de nós e deles melhores pessoas, seres mais conscientes, mais amorosos, mais completos. Não lutando para serem hoje os adultos que só poderão ser mais à frente.

Em cada momento fluir com eles, sem preconceitos, esforçandonos por desconstruir as ideias feitas, as crenças, as teorias. Tudo aquilo que nos pode aprisionar e nos limita. Não as ignorando ou rejeitando, por serem elas que sustentam em parte o nosso mundo e por também nos poderem permitir uma visão crítica, que possa ser transformadora. Descobrindo em cada momento como as teorias nos servem, como nos fecham, como nos magoam. Construindo a partir dessa experiência as nossas individuais e coletivas teorias e convicções, que servem o momento, eventualmente os momentos seguintes, mas que certamente terão de ser revistas, em momentos que nos exigem outras. E sobretudo não fazer da liberdade apenas um fim, mas um aliado do momento.

Simples! Sempre chego à conclusão que é na simplicidade que está a resposta. Depois e enquanto o caminho da complexidade se desdobra, percebendo camadas sobrepostas a outras camadas e a elas interligadas. Uma complexidade cuja compreensão nunca será plena. Por extravasar a nossa capacidade de apreendê-la. Sim, a nossa liberdade detém-se quando resvala no nosso limite de ir mais além. Embora não tenhamos de ficar parados, pois o limite é uma membrana elástica que se pode distender e no seu interior há um organismo que se expande. A vida é simples se atentamos ao maravilhoso de um simples respirar, onde permanentemente nos doamos à vida e ela, através de nós, se expressa. Num movimento que, em nosso quotidiano é reflexão e intuição ao mesmo tempo.

A alguém, talvez também a nós, e ao nosso mundo, será necessária a guerra, a desigualdade, o sofrimento, a violência, a desarmonia. 
Pelo menos enquanto delas nos alimentarmos (até para lutarmos contra elas) e enquanto não encontrarmos outra fonte de alimento que nos sacie plenamente. Talvez um caminho mais construtivo esteja não em lutar contra, embora este seja legítimo, mas substituir o alimento por outro. Criar a paz, a abundância, o amor dentro de nós, mesmo que na génese e por contraposição a sua matéria-prima fosse a carência, o medo, a raiva. Usar a energia imensa, que daqui nasce, ao serviço de algo que as transforme no seu oposto.

Porque os opostos se encontram. No cerne da tristeza podemos encontrar-nos face a face com a alegria. Na porta que nos separa encontramos a entrada para outra coisa. Talvez o Mal, o verdadeiro mal, resida na separação. Não uma separação total, que não seria possível. Mas uma separação, mesmo assim, que desejamos. Na ânsia de sermos diferentes e melhores que o outro, separamo-nos. Na ignorância de sermos ligados, desligamo-nos. No medo de sermos destruídos, fugimos ou lutamos, destruindo os laços. Mas a realidade é mais forte que o nosso desejo, a nossa ignorância, o nosso medo. A realidade é ligação, relação, amor, interconexão, união. Haverá sempre, por detrás de todos os fios cortados fios mais finos, invisíveis, que se repõem. O movimento, que é alicerce do mundo, repõe os fios. Por isso, acredito, a Vida sempre vencerá, o Bem que é a Vida e a relação entre os seres, a unidade infinita, superará qualquer mal. Pequenos males, que nos parecem grandes males, e que fazem a roda girar, mantendo o movimento. Mas o que nos parece verdadeiramente importante ser preciso compreender é que o Bem, como movimento criativo e de religação, reporá a Unidade.

A criatividade é importante, mas por si só não é garante de bondade, compaixão, verdade, justiça. No plano do humano vivente em sociedade, nesse plano, é necessária uma atenção vigilante sobre nós próprios, com os outros. Uma vigilância que é de algo em nós que sobrevoa as nossas emoções, as nossas intuições, as nossas motivações, as nossas racionalizações e que as escrutina questionando-nos. Um segundo olhar, uma voz interior, uma reflexividade que descobre, no conflito entre essas dimensões, um objeto para o qual olhar. Com a coragem e a vontade de 
repor o equilíbrio, de alinhar-nos com esse ser em nós que nos desafia. Porque o desequilíbrio e o desconforto físico, a tristeza ou a raiva, a vergonha ou o arrependimento, o conflito cognitivo, o pressentimento são sinais que o corpo, a razão, a emoção, a intuição, em nós, nos dão para a reflexão ética. Mas também a compaixão, a empatia, a compreensão e a sensibilidade ao outro. Também aquilo que ele nos diz, pela palavra, pelo gesto, pelo silêncio. E ainda, o que o mundo nos mostra. Porque como muitos filósofos, entre os quais Habermas (1999) e Cortina (1986) nos dizem, é pelo diálogo, sustentado por um sentido de cuidado, solidariedade, cooperação e reconhecimento mútuos, que é possível construir uma sociedade participativa, uma democracia radical, uma cidadania madura, porque reflexiva e não apenas ativa, uma ética onde a justiça é compartilhada e onde a dignidade de todos e a liberdade é conquistada solidariamente com os outros.

Para estes e outros autores (dos quais me sinto próxima embora não totalmente coincidente), trata-se de um projeto social e politico, uma utopia realista, assente numa intencionalidade transformadora e emancipatória, tendo como horizonte a possibilidade de uma ética universalista mínima. Esta será uma forma de aliança entre razão e compaixão, de aceitar o pluralismo enquanto se busca a unidade, pelo acordo intersubjetivo e pelo consenso. A esperança numa ética global.

Acrescentarei a tudo isto a necessidade, o dever moral, enquanto compromisso com esse sentido interior que não é fechado na pessoalidade e nos seus interesses particulares, que vê para além do interesse imediato do outro quando fechado apenas em si, que não se fixa apenas no interesse da maioria ou das instituições em que nos movemos. Um sentido interior que nos habita e que pode até reforçar, mas também pode levar-nos a renunciar a tudo isso. Uma certeza, que não nos é dada mas que implica o esforço de a sentirmos, de nos alinharmos com ela, uma vez e outra ainda. Até que se instale. Embora mesmo dela seja preciso distanciar-nos, sobretudo aí, quando a certeza se instala, desconfiando dela e da naturalização com que a sociedade nos imprime essa certeza, 
desconfiando de nós, de uma possível arrogância e de um autoengano. Assumindo, pois, a certeza da incerteza e o autoquestionamento.

É essa a nossa força e a nossa fragilidade, esse inacabamento, esse constante trabalho de Sísifo subindo a montanha. Nós sujeitos das nossas histórias, aprendizes a vida toda, nada podendo dar por certo e adquirido para sempre.

E é esse o desafio da Realidade da vida, sempre nos colocando na frente, no nosso quotidiano concreto, as situações, as pessoas, nossos alunos, colegas, pais, parceiros de outras instituições, com quem viveremos as histórias que nos colocarão à prova, que nos obrigarão a repensar as nossas crenças, que nos estimularão a seguir os nossos impulsos, a correr riscos, a aprofundar os nossos dons e com quem poderemos desenvolver os projetos que nos levarão juntos a construir um mundo mais justo, mais responsável e solidário.

Mas, dir-me-ão: como partir daqui para essa utopia de um mundo mais justo, a nível planetário?

A História sempre nos mostra a luta entre justiça e injustiça, entre a compaixão e a indiferença, entre paz e violência. A dinâmica da História não nos parece mostrar que caminhamos no sentido de um progresso linear, não sendo certo que a Humanidade seja hoje melhor que nos séculos e milénios antes. Dirão alguns que, por detrás da aparência, onde o Mal parece estar a vencer, há um Bem que se prepara e que já é ganho, embora não inteiramente visível, sendo para tal fundamental todo o trabalho dos homens de bem, a esperança que sempre se manteve viva nos seus corações, a invocação e manifestação de uma inteligência maior. Atravessamos um período negro e crítico na História da nossa civilização, até porque num mundo global se digladiam distintos projetos humanos. Vivemos na bifurcação e na imprevisibilidade, não sabendo qual o rumo que seguiremos. Mas a História também nos mostra que as civilizações morrem e depois delas novas vêm em seu lugar. Cabe-nos, a todos nós, preparar o que aí vem, semeando hoje o que iremos colher mais tarde, enquanto Humanidade. Para que não seja ainda desta o seu fim neste lindo 
planeta. Para que ao cuidar dele no presente cuidemos do futuro. Criando pontes em vez de muros. A cada um a responsabilidade do futuro.

Uma esperança, um cuidado e uma responsabilidade que implicam uma análise não ingénua das relações de poder, e das lógicas dos sistemas, das opressões e contradições em que vivemos imersos...

A cada um, e a todos nós, cabe olhar com discernimento para os sistemas, as instituições, as suas estruturas e dinâmicas, e aliar a esse olhar, discernimento e compreensão, que a razão e o conhecimento favorecem, a coragem, a vontade e a ação que denuncia, contesta e contrapõe outras ordens, outros princípios e valores, resistindo à barbárie e à crueldade. No nosso quotidiano, na educação onde nos movemos, nas escolas em que participamos e gerimos, nos sistemas e estruturas que mantemos, envolver-nos a nós e aos outros numa crítica radical que favoreça uma conscientização política e pessoal e uma autonomia que nos liberta.

Por isso acreditamos nos projetos em que participamos juntos na pesquisa e na ação, à procura de clarificar e aprofundar os valores que nos movem, as decisões que nos afirmam, as ações que nos alinham com os outros e connosco próprios, as instituições que nos suportam e espelham. Criando de dentro, instituições que aprendem e cuidam e onde o poder se possa exercer com respeito, compaixão, justiça e responsabilidade. Instituições que cooperam com outras, dentro de comunidades culturalmente diversas, e que através de processos locais se tornam forças transformadoras.

\section{Pesquisas sobre ética e formação de professores no Instituto de Educação da Universidade de Lisboa - projeto de investigação "Pensamento e Formação ética-deontológica de professores"}

Parece-nos constituir uma condição necessária, embora não suficiente, que os principais responsáveis pela educação escolar dos alunos - os professores - através de um processo de tomada de consciência de si, dêem visibilidade, perante si e perante os outros, às suas concepções ético-deontológicas, às suas dificuldades e interrogações, às suas necessidades e desejos de formação neste domínio (ESTRELA, 2010, p. 12) 
Procurarei assim dar conta de algumas das nossas pesquisas sobre formação de professores. Centro-me no projeto de investigação "Pensamento e Formação ética-deontológica de professores", coordenado por Maria Teresa Estrela, e em pesquisas que lhe deram continuidade, estão na sua esteira ou com ele se relacionam de algum modo. O projeto, financiado pela FCT, desenhou-se e desenvolveu-se em duas etapas principais, concluídas. Uma primeira etapa visando, sobretudo, conhecer o pensamento ético-deontológico dos professores de diversos níveis de ensino, bem como a sua atitude em relação à formação ética. Uma segunda etapa subsequente centrada na testagem de esquemas de formação ética de professores, onde os professores, em processo de investigação-ação, refletem sobre si próprios, os seus alunos e colegas, as suas instituições, a sua própria profissão, e o sistema educativo, analisando com um olhar crítico e ético, procurando pela ação transformar-se, aos outros e aos seus contextos.

A investigação teve continuidade, já após a finalização do projeto financiado, numa 3. e 4. etapas. Desenharam-se novos casos de formação, onde se procurou aprofundar a dimensão da investigação dos professores e se pretendeu explorar novos processos de formação, e numa $4^{\mathrm{a}}$ etapa iniciou-se uma pesquisa sobre os processos de desenvolvimento profissional e a construção identitária dos formadores de professores envolvidos.

Assim, na primeira etapa realizaram-se entrevistas e aplicou-se um questionário, obtendo dados de 1235 professores de todos os níveis de ensino (desde o pré-escolar ao ensino superior, inclusive), em três regiões de Portugal (foram feitas entrevistas a 40 professores e o tratamento destas entrevistas permitiu a elaboração de um questionário, aplicado numa pré-testagem a 123 professores e revisto para ser depois aplicado em extensão, com um retorno de cerca de 1112 respostas).

Os resultados da primeira fase, no que respeita aos professores do pré-escolar e ensinos básico e secundário, apontam para o reconhecimento das dimensões éticas da profissão, a recusa maioritária do subjetivismo ético (isto é, de a ética ser um assunto pessoal e diverso de 
indivíduo para indivíduo), a aceitação da relatividade histórico-social da ética (variável consoante as épocas e contextos sociais), o reconhecimento do empenho no desenvolvimento ético dos alunos, uma atitude favorável face à formação e às modalidades de formação experiencial, com partilha e reflexão sobre situações do quotidiano; a concordância da maioria quanto à desejabilidade de um código deontológico (o que pode corresponder a um maior profissionalismo, desejo de maior autonomia da tutela ou maior necessidade de regulação face aos problemas). Os dados salientam ainda correlações e relações: a) entre os valores de conduta do professor e os que pretende desenvolver nos alunos (com destaque para o respeito, responsabilidade e justiça); b) correlações entre uma parte das estratégias que dizem usar para o desenvolvimento ético dos alunos e aquelas que desejariam na sua formação profissional no domínio da ética. Verificam-se também perspetivas diferenciadas entre os professores, nomeadamente: 1) entre uma ética racionalista e universalista (com dominância da razão e da normatividade) e uma contextualista e particularista (onde a dimensão do sentimento, do cuidado e da benevolência dominam), 2) entre a ideia de uma ética inata e de uma ética adquirida, 3) entre a justiça enquanto igualdade (de regras e procedimentos, baseada na validade universal de princípios e valores) e enquanto equidade (com clara valorização da equidade, enquanto justiça que atua de acordo com a diversidade de condições e as necessidades específicas dos indivíduos e grupos), 4) entre o bem centrado no aluno e o bem centrado no processo e nas suas condições. Foram analisados também dilemas e problemas (este últimos não podendo ser considerados dilemas por não porem uma opção entre duas alternativas cuja escolha provoca sempre algum desconforto), dilemas e problemas indiciadores de alguma tensão, que podem ser organizados em diferentes categorias: o profissionalismo no sentido restrito do termo, o sistema educativo, a escola, a família dos alunos, a família dos professores, a formação contínua, o currículo e avaliação, a relação interpessoal (sobretudo, com alunos, com colegas...). Os dilemas mostram que os professores vivem dificuldades objetivas, nomeadamente no que respeita à diferenciação em sala de aula e à colaboração entre todos 
os intervenientes. As dificuldades de integração mostram que a grande discussão ao nível da justiça é saber até que ponto é possível conciliar a integração de determinados alunos com uma escola exigente e de qualidade. Uma grande parte dos dilemas situa-se nessa conflitualidade entre o cumprimento de regras de justiça - que os professores, por vezes, entendem como deveres legais, e por isso entram em conflito com os diplomas legais, as burocracias... - e a resposta aos casos concretos, fazendo deste modo emergir uma noção contextualizada de justiça (CAETANO; AFONSO, 2009). Dilemas cuja superação pode passar por sair de uma lógica linear e por construir, segundo uma lógica ternária e de terceiro incluído, em busca de uma terceira via, que pode significar a aceitação da contradição, a criatividade que daí decorre.

Numa segunda etapa, procedeu-se ao desenvolvimento de cinco situações de formação ética de professores e testaram-se algumas formas organizativas e atividades de formação, (parcialmente comuns, mas com as devidas adaptações aos contextos e intervenientes específicos), tendo como uma das principais questões compreender como é que a investigação-ação como estratégia de formação centrada na ética promove mudanças nos professores.

Em nenhum dos casos de formação se seguiu uma lógica aplicativa de conceções éticas defendidas a priori pela equipa do projeto, mas procurou-se fazer o aprofundamento das próprias problemáticas dos professores envolvidos na formação, sendo autores, coautores dos seus projetos.

Nos primeiros casos, definimos uma linha de ação multidimensional e multireferencial, que conjugava uma vertente conceptual, pela clarificação e debate de conceitos, de princípios/valores e de perspetivas teóricas; uma vertente investigativa, pela observação, análise e reflexão de situações concretas; e uma vertente processual e experiencial, pela qual os professores eram chamados a experimentar e a partilhar, durante a formação, processos que poderiam transferir para os seus contextos profissionais. 
Princípios, valores e objetivos foram objeto de reflexão, quer de forma abstrata quer de forma situada, pensados no geral e no particular, contextualizados por referência a situações concretas mas também questionados e sinalizados para a elaboração de cartas de princípios coletivos (CAETANO, 2010a).

Privilegiámos uma perspetiva de formação assente numa ética de discussão, mobilizadora de visões éticas deontológicas e teleológicas.

A teoria e a prática foram constantemente postas em diálogo, quer pela reflexão prática das implicações de conceitos e conceções teóricas, quer pela reflexão a partir das práticas dos professores e de experiências ocorridas durante as sessões de formação. Em alguns casos fez-se uma abordagem à temática do código deontológico e num outro aprofundou-se mais a articulação entre ética profissional e formação ética dos alunos (CAETANO, 2016).

Ainda no que respeita às atividades de formação realizadas, pautada pela diversidade, salientamos concretamente a análise de resultados de investigação, a análise da legislação, a leitura e debate de textos em termos conceptuais e em termos das suas implicações para a prática, a elaboração de muros de valores (baseado na atividade "The wall”, descrita por Korthagen et al. 2001), o desenvolvimento de projetos colaborativos de intervenção e de investigação e o esboço de cartas de princípios, o debate e partilha de experiências, nomeadamente de situações dilemáticas concretas, a simulação e a modelização sistémica desses dilemas.

Em relação a esta metodologia da modelização sistémica (CAETANO, 2015b), uma breve síntese para dizer que consideramos este processo uma forma de apropriação dos sistemas que começa pela reflexão e observação, com recolha e análise de dados, dados esses que são, num processo de simbolização gráfica, organizados, primeiro representando sistemas e intervenientes; segundo integrando processos de comunicação e decisão, e por fim agregando os significados dos diversos intervenientes, seguindo-se uma revisão com os próprios professores e uma possível posterior ampliação de dados para novas modelizações. 
Numa situação de formação mais recente, pretendeu-se, ainda, explorar formas de promover o desenvolvimento de comunidades justas, eticamente mais coerentes e conscientes, visando favorecer uma dimensão crítica e transformadora a nível institucional, que extravasasse a formação e os professores nela envolvidos.

Partiu-se do pressuposto de que uma análise de documentos normativos a nível do sistema educativo (lei de bases, estatuto da carreira docente, estatuto do aluno) e a nível das escolas (projeto educativo, regulamento interno) faria emergir questões, problemas e dilemas que favoreceriam a reflexão conjunta e o desenvolvimento de projetos de investigação e de mudança coletiva. Numa perspetiva aberta, seriam os professores a definir as problemáticas, os processos e a utilização dos resultados das suas pesquisas. Previa-se, como cenários possíveis, a elaboração de propostas de redefinição de normativos, a elaboração de uma carta de princípios éticos para as suas escolas, a disseminação de resultados de um modo participado, envolvendo a comunidade educativa, numa reflexão crítica e na procura conjunta de soluções, e/ou ainda a possível criação de um grupo de ética, constituído por uma rede de professores de diversas escolas, e apoiados numa plataforma virtual (espaço que se iniciou e desenvolveu durante a formação).

A disponibilização de materiais teóricos na plataforma e o seu debate nas sessões foram feitos de acordo com as problemáticas dos projetos, assinalando-se a nível ético temas relativos à felicidade e bem do aluno, justiça e igualdade, responsabilidade e respeito, diversidade e reconhecimento do outro.

Tendo em conta o conjunto dos casos estudados, os processos e sua interdependência complexa parecem promover mudanças, em especial nos professores diretamente envolvidos na formação, enquanto profissionais e enquanto grupo (CAETANO, 2010a, 2010b). Verifica-se, efetivamente, uma complexificação dos discursos dos professores, nomeadamente no sentido de uma contextualização do pensamento e reflexividade da ação, bem como de organização dos saberes em visões mais abrangentes, embora diversas entre os professores. Existem também 
indicadores no sentido de uma maior abertura, flexibilidade e questionamento permanente, tendo em conta a imprevisibilidade das situações, a natureza simultaneamente contraditória e religada da realidade e o carácter provisório e limitado do conhecimento possível. Trata-se de desenvolver um comprometimento com uma ação eticamente orientada. Trata-se, ainda, de favorecer a dimensão coletiva, mais nuns casos do que noutros, onde o trabalho conjunto, o diálogo e os projetos de investigação são nucleares para o desenvolvimento de dinâmicas colaborativas e para o desenvolvimento das instituições, a nível ético, considerando que:

o objecto primário da justiça é a estrutura básica da sociedade, ou, mais exactamente a forma pela qual as instituições sociais mais importantes distribuem os direitos e deveres fundamentais e determinam a divisão dos benefícios da cooperação em sociedade (...) (RAWLS, 1993, p. 30).

No que respeita ao estudo sobre desenvolvimento profissional e construção identitária dos formadores, publicámos recentemente, em livro da editora Appris, intitulado "Formação de Professores no Brasil e em Portugal. Pesquisas, debates e práticas", um capítulo onde se questiona o duplo papel dos formadores que são simultaneamente professores nas suas escolas (CAETANO, 2015a). Os principais resultados apontam para o isomorfismo entre estes papéis, bem como para algumas especificidades. O diálogo entre professores-formandos, formadores de professores e pesquisadores de retaguarda, bem como o trabalho concomitante dos formadores de professores em ambos os contextos (escolas e projeto de formação), propiciou uma espécie de recursividade, favorecendo a convergência de disposições, saberes e práticas. O estudo acentua a complexidade identitária dos formadores, na medida em que as suas identidades profissionais se revelam múltiplas e enfatiza a importância de comunidades colaborativas entre professores e formadores e de comunidades de aprendizagem profissional entre pares de formadores, espaços íntimos e seguros de partilha, de autoformação e suporte para lidar com as vulnerabilidades e inseguranças, onde é possível desafiar rotinas, arriscar o movimento de se perder para se encontrar e onde a investigação, a reflexão 
e a relação são processos importantes de aprendizagem profissional, de empoderamento e de autonomização (CAETANO, 2015a).

\section{Projetos em curso}

a transformação dos nossos sentimentos e aspirações precisa das suas práticas específicas, focando-se na nossa habilidade de integrar os nossos motivos altamente díspares e contraditórios, mudar os nossos habituais padrões de emoção e ter contato com um sentido de realidade e propósito das nossas vidas que seja mais alargado e profundo dos que as normais respostas à nossa experiência social e pessoal (WINTER, 2011, p.69)

Atualmente continuo a orientar doutoramentos e pós-doutoramentos onde a dimensão ética da docência e a sua formação são aprofundados.

Relembro, a título de exemplo, o trabalho de Mariana Feio (2015), que recentemente defendeu a sua tese de doutoramento e onde procurou articular o tema da ética na formação de professores e de alunos, uma tese parcialmente integrada e desenvolvida durante o curso do projeto anteriormente referido. Assumindo uma metodologia de investigação-formação no seio da qual os professores envolvidos desenvolveram projetos de investigação-ação com os seus alunos, desenhou uma sequência de 4 etapas de trabalho empírico com os professores, com dois ciclos de investigação-ação alternados com momentos de follow up e de acompanhamento mais individualizado. Conclui que a dupla preocupação com os alunos e consigo próprios, enquanto profissionais da educação, a experiência de estratégias que servem ambos, embora com adaptações, o isomorfismo entre processos de investigação-formação e investigação -ação, o desenvolvimento de projetos onde os próprios alunos são chamados a serem parte ativa na análise e solução de problemas constituem processos centrais no sucesso da formação. Realce ainda para a dimensão colaborativa, pela qual contam com o formador como amigo crítico no desenhar e desenvolver dos seus projetos, bem como na elaboração destes em conjunto e com vista ao desenvolvimento da organização escolar, no 
sentido de um êthos democrático em que todos participam ativamente na sua transformação.

Também num trabalho de pós-doutoramento realizado com Adriana Loss (LOSS e CAETANO, 2015), a dimensão ética dos educadores e professores foi trabalhada, em articulação e de forma transversal a três temas centrais - o das dimensões ou consciências intrapessoal, social e profissional. Aqui o trabalho com as narrativas e com as expressões artísticas foi central no desenvolvimento de oficinas de formação. Embora não se tenha seguido um esquema de investigação-ação, desenvolveu-se um trabalho de investigação-formação, organizado em dois ciclos, o primeiro dos quais ocorrido com um grupo no Brasil e o outro com dois grupos em Portugal. Os resultados apontam para a importância da ética, exploradas nas três vertentes atrás referidas, considerando os formandos que as discussões havidas nos grupos, as leituras efetuadas sobre ética e profissionalismo, a escrita de narrativas, a teatralização de dilemas e tensões éticas, contribuíram fortemente para o questionamento dos seus valores, para uma compreensão mais alargada, para o fortalecimento de algumas convicções... Do ponto de vista da complexidade, estes resultados acentuam, mais uma vez, a importância do diálogo onde diversas perspetivas se confrontam, novas questões se equacionam, visões distintas se enriquecem mutuamente. A multireferencialidade de fontes teóricas que são objeto de aprofundamento e de reflexão individual e de debate coletivo são também um aspeto central que favorece um trabalho sobre si próprio na relação consigo, com o outro, com a profissão, seus contextos e aqueles que nela se cruzam. Destaque ainda para as expressões, como a poesia e o teatro, através das quais é possível usar outras linguagens que rompem com leituras mais prosaicas e provocam novos olhares, uma sensibilidade outra, uma busca de sentidos na própria existência, o desbloquear de enclausuramentos individuais, o desdramatizar de situações...

Em curso e fase de conclusão, o doutoramento de Sheyla Macedo, desenvolvido empiricamente numa universidade do Brasil, na formação inicial de pedagogos, que já está a trazer novos contributos em termos de pesquisa teórica e através de publicações conjuntas (MACEDO; 
CAETANO, 2017), e que trará novos aprofundamentos e recomendações para a formação ética de pedagogos, com base nas experiências e perceções dos estudantes, professores e egressos.

\title{
Reflexão final - A formação ética de professores à luz das perspetivas da complexidade
}

\begin{abstract}
Precisamos tomar consciência sobre a necessidade de uma nova compreensão acompanhada de uma nova ética, mas de uma ética ecológica, a ética do respeito, da solidariedade, da convivência; a ética das relações que reconhece a interdependência dos fenómenos, a ética que nos une e, ao mesmo tempo, renova nossos compromissos e obrigações com as futuras gerações (MORAES, 2010, p.88)
\end{abstract}

Em jeito de síntese final, pensar ética de forma complexa é, parece-me a mim, desde logo uma inevitabilidade, embora o pensamento complexo tenha múltiplos níveis e possamos sempre contrapor limitações a este pensamento e às visões por ele construídas, decorrentes da própria limitação da nossa capacidade cognitiva e de todos os constrangimentos pessoais e sociais que nos condicionam. Entendendo que aprofundar a complexidade significa simultaneamente alargar, integrar e reconstruir numa ordem nova que reorganiza e inclui novas dimensões, ao mesmo tempo que se mantém em aberto e se aprofunda.

Pensar a complexidade na formação de professores partindo de uma reflexão sobre o que se fez e o que ainda se poderá fazer para continuar e ir mais longe no desenvolvimento dessa complexidade coloca-nos múltiplos desafios que não seria possível dirimir no espaço de uma conferência mas em relação a alguns dos quais vos proponho refletir.

Antes de mais importa considerar a transdisciplinaridade, multireferencialidade de fontes e a multidimensionalidade da ética e da formação ética de professores, nas suas vertentes individuais e coletivas, pessoais e profissionais, interpessoais e transpessoais, culturais e políticas, ambientais e societais. Consideramos a ética e a moral como partes de um mesmo, num vai e vem recursivo entre o concreto e o abstrato, entre 
o singular e o universalizável, entre os processos e os conteúdos, entre os princípios e finalidades, entre as virtudes e os valores, entre os propósitos e as consequências, entre a reflexão e a ação, entre as teorias, as normas e regras sociais. Consideramos que os seus fundamentos e justificações são racionais mas também intuitivos, afetivos e emocionais, que as decisões são individuais mas também coletivas, e que, nestas, o conflito, a contradição e a ambivalência são motores para o questionamento e aprofundamento, dos quais pode emergir (mas não necessariamente), uma consciência ética mais ampla e integradora e, nesse sentido, mais complexa. Entendemos que mesmo os processos individuais são feitos em contexto e em interpelação, sendo portanto importante a dimensão intersubjetiva, a argumentação, o discurso. Sem que isso implique uma ditadura da palavra e do coletivo, mas implicando ainda o respeito pelo silêncio, o lugar para o recolhimento, a liberdade da recusa e de fazer diferente...

Daqui também a dificuldade em assumir um modelo, antes de mais abrindo possíveis cenários que se esperam sejam expandidos, transformados por se tornarem mais complexos ou ao invés mais simples, indo ao encontro daqueles com quem nos cruzamos e que os propõe de cada vez.

Modelizar como um processo de tentativa e erro, que parte do que já é para compreender, que assume o que funciona como ponto de partida, que opera no ideal do que ainda não foi possível mas que poderá ser desejável de acordo com o que se teoriza.

Pode ser ou não pela investigação-ação, pois esta transporta consigo exigências e fragilidades que não se coadunam com uma generalização em extensão. Conhecer e compreender para transformar, transformar para conhecer e compreender, duas premissas que têm de ser desconstruídas. O primado do conhecimento, da compreensão e da ação, que aqui se vislumbra, precisa de ser questionado. Porque a imaginação também importa, porque o sentir emocional e sensorial também nos servem de referência para a decisão, porque o fruir e o fluir eticamente com os outros e com o todo em que nos situamos é muitas vezes mais uma dança não previamente consciente do que uma decisão assumida antes de agir. 
O próprio diálogo pode ser uma ditadura, numa dinâmica de poderes que não são igualitários e onde a persuasão de alguns assenta numa capacidade argumentativa e numa experiência que a outros falha. $O$ consenso pode ser a abdicação de alguns, mais do que a convicção de todos, para evitar o conflito e a separação. A competitividade e o desejo de destruir mais do que de construir podem minar o pressuposto de que estamos todos por bem e para o bem.

Por isso os modelos servem para o que servem e não para mais do que isso - servem como mapas para nos guiar, mostrando estradas nas quais confluem muitos atalhos e caminhos secundários e por onde podemos e devemos circular; servem como sinalizadores de lugares onde podemos deter-nos para neles pernoitar ou merendar ou explorar ou distrair-nos; servem como indicadores de obstáculos que podemos contornar, escalar ou perfurar. Servem, em suma, como testemunhos de quem já a eles chegou por ter feito um reconhecimento prévio, de ter feito a experiência e os ter desenhado a partir dela. E depois somos nós, cada um de nós, em conjunto com outros, que nos aventuraremos pelo território, fazendo o nosso próprio percurso e a nossa experiência única, podendo depois contá-la, redesenhar o mapa, e inscrever nele novos lugares e informações, contribuindo assim para que outros dele usufruam. É assim que evolui a Ciência, o Conhecimento, a Humanidade.

O laço com o outrem só se aperta como responsabilidade [...] Dizer: eis-me aqui. Fazer qualquer coisa por outrem. Dar. Ser espírito humano é isso. A encarnação da subjetividade humana garante a espiritualidade (LEVINAS, 2007, p. 81)

\section{Referências}

CAETANO, A. P. Das necessidades de formação à concepção dos casos de formação. In: ESTRELA, M. T.; CAETANO, A. P. (Orgs.). Ética profissional docente: do pensamento dos professores à sua formação. Lisboa: Educa, 2010a. p. 114 - 120. 
CAETANO, A. P. Da análise conjunta de todos os casos de formação, á sua modelização. In: ESTRELA, M. T.; CAETANO, A. P. (Orgs.). Ética profissional docente: do pensamento dos professores à sua formação. Lisboa: Educa, 2010b. p. 157 - 170.

CAETANO, A. P. Ser professor e formador de professores: a complexidade de um duplo papel. In: LOSS, A.; CAETANO, A. P.; PONTE, J. P. (Orgs.). Formação de professores no Brasil e em Portugal: pesquisas, debates e práticas. Curitiba: Appris, 2015a. p. 31-53.

CAETANO, A. P. A modelização sistémica de dilemas profissionais na formação ética de professores. In: BEHRENS, M. A.; ENS, R. T. (Orgs). Complexidade e transdisciplinaridade: novas perspectivas teóricas e práticas para a formação de professores. Curitiba: Appris, 2015b. p. 271-294.

CAETANO, A. P. Formação de professores e ética profissional na promoção de comunidades de prática. In: MEDEIROS, E. (Org). Formação pluridimensional de educadores e professores em dinâmicas de intervenção educacional: currículo(s), cultura(s) e saberes na sociedade do conhecimento. Lisboa: Piaget, 2016. p. 147-161.

CAETANO A. P.; AFONSO, R. A justiça e os dilemas na formação ética de professores. Educação, v. 32, n. 3, p. 252-259, 2009.

CORTINA, A. Ética mínima: introducción a la filosofia práctica. Madrid: Anaya, 1986.

ESTRELA, M. T. Introdução e apresentação do projecto. In: ESTRELA, M. T.; CAETANO, A. P. (Orgs.). Ética profissional docente: do pensamento dos professores à sua formação. Lisboa: Educa, 2010. p. 9 -21.

FEIO, M. A formação ética de professores no cruzamento com a formação ético-moral de alunos: o papel da investigação-ação. Tese (Doutorado em Educação) - Instituto de Educação da Universidade de Lisboa, Lisboa, 2015.

HABERMAS, J. Comentários à ética do discurso. Lisboa: Instituto Piaget, 1999.

KORTHAGEN, F. Linking practice and theory: the pedagogy of realistic teacher education. New Jersey: Lawrence Erlbaum Associates, 2001. 
LEVINAS, E. Ética e infinito. Lisboa: Edições 70, 2007.

LOSS, A.; CAETANO, A. P. A autoformação e a ética do ser educador. Atas do Congresso XII Congresso Nacional de Educação - EDUCERE, 26 a 30 Outubro 2015.

MACEDO, S.; CAETANO, A. P. A Ética como competência profissional na formação: o pedagogo em foco. Educação \& Realidade, Porto Alegre, v. 42, n. 2, p. 627648, fev. 2017. http://dx.doi.org/10.1590/2175-623656078.

MORAES, M. C. Complexidade e currículo: uma relação necessária. In: ALMEIDA, C.; PETRAGLIA, I. (eds). Estudos de complexidade. São Paulo: Xamã Editora, 2010. p. $75-89$.

MORIN, E. La méthode 6. Éthique. Paris: Seuil, 2004.

RAWLS. J. Uma teoria da justiça. Lisboa: Editorial Presença, 1970.

WINTER, R. Power, freedom, compassion. Transformations for a better world. Cambridge: Willow Tree Press, 2011.

Recebido: 30/04/2016

Received: 04/30/2016

Aprovado: 30/05/2016 Approved: 05/30/2016 
